\title{
The Influence of Annealing Temperature and Time on the Formation of $\delta$-Phase in Additively- Manufactured Inconel 625
}

\author{
M.R. STOUDT, E.A. LASS, D.S. NG, M.E. WILLIAMS, F. ZHANG, C.E. CAMPBELL, \\ G. LINDWALL, and L.E. LEVINE
}

\begin{abstract}
This research evaluated the kinetics of $\delta$-phase growth in laser powder bed additively-manufactured (AM) Inconel 625 during post-build stress-relief heat treatments. The temperatures ranged between $650{ }^{\circ} \mathrm{C}$ and $1050{ }^{\circ} \mathrm{C}$, and the times from 0.25 to 168 hours. The presence of $\delta$-phase was verified for each temperature/time combination through multiple techniques. A conventional time-temperature-transformation diagram was constructed from the time-temperature data. Comparison to the growth in wrought IN625 with a similar nominal composition revealed that $\delta$-phase formation occurred at least two orders of magnitude faster in the AM IN625. The results of this study also revealed that the segregated microstructure in the as-built condition has a strong influence on the kinetics of $\delta$-phase formation in AM IN625 as compared to a homogenized material. Since control of the $\delta$-phase growth is essential for reliable prediction of the performance of IN625 components in service, avoiding heat treatments that promote the formation of $\delta$-phase in AM components that are not homogenized is highly recommended. This will be particularly true at elevated temperatures where the microstructural stability and the consistency of mechanical properties are more likely to be affected by the presence of $\delta$-phase.
\end{abstract}

https://doi.org/10.1007/s11661-018-4643-y

(C) The Minerals, Metals \& Materials Society and ASM International 2018

\section{INTRODUCTION}

ADDITIVE manufacturing (AM) is a transformative technology that has opened areas of design space that were previously inaccessible. It facilitates production of complex, three-dimensional parts with intricate geometries that often prove to be too costly, difficult, or in some cases, impossible to produce using traditional subtractive manufacturing processes. ${ }^{[1-3]}$ However, the extreme build conditions in the AM process, e.g., cooling rates ranging from $10^{3}$ to $10^{6} \mathrm{~K} / \mathrm{s}$ and repeated heating/cooling cycles, can create deleterious microstructures featuring high residual stresses, extreme compositional gradients, and unexpected phases. ${ }^{[4,5]}$ Accepted heat treatments based on nominal powder

M.R. STOUDT, E.A. LASS, M.E. WILLIAMS, F. ZHANG, C.E. CAMPBELL and L.E. LEVINE are with the Material Measurement Laboratory, National Institute of Standards and Technology, Gaithersburg, MD 20899. Contact e-mail: stoudt@nist.gov D.S. NG is with the Materials Science and Engineering Department, Northwestern University, Evanston, IL 60208. G. LINDWALL is with the Department of Materials Science and Engineering, KTH Royal Institute of Technology, Brinellvägen 23, 10044 Stockholm, Sweden.

Manuscript submitted December 19, 2017.

Article published online May 10, 2018 compositions and equilibrium phase diagrams may be ineffective or even produce microstructures that severely degrade the mechanical performance and lifetime of the AM-produced part.

Inconel 625 (IN625) is a well-characterized solid-solution strengthened, nickel-based super alloy that is commonly used for AM applications, largely due to its desirable properties (e.g., weldability, creep resistance, and corrosion resistance). However, the literature indicates that the pronounced segregation of solute elements during solidification increases the likelihood of the precipitation of various secondary intermetallic phases such as $\delta$-phase $\left(\mathrm{D}_{\mathrm{a}} \mathrm{Ni}_{3} \mathrm{Nb}\right), \gamma$ ", Laves phases, and carbides that influence the properties during service. $^{[6-9]}$ An investigation of the IN625 as-built microstructure produced using laser powder bed fusion (L-PBF) revealed that the segregation during solidification promotes $\mathrm{Nb}$ and Mo enrichment in the inter-dendritic regions, while the dendrite cores were enriched in $\mathrm{Ni}$ and $\mathrm{Cr}^{[10]}$ Recent CALPHAD and phase-field modeling also suggested significant micro-segregation in IN625 produced using L-PBF $\mathrm{AM} .^{[11,12]} \mathrm{A}$ study of the microstructural evolution in AM-built IN625 produced by L-PBF revealed that a significant volume fraction of the orthorhombic $\delta$-phase formed during an industry-recommended, 
post-build stress-relief anneal of 1 hour at $870^{\circ} \mathrm{C} .^{[13]}$ This phase is known to form as fine platelets within the Nb-rich inter-dendritic regions of the as-built microstructure. ${ }^{[4]}$ While some literature accounts suggest that $\delta$-phase enhances the tensile strength in IN625, it is widely considered to be undesirable because it decreases the ductility, the fracture toughness, and the corrosion resistance of wrought IN625. ${ }^{[9,14-16]}$

The transformation kinetics in an alloy may be summarized with a time-temperature-transformation (TTT) diagram, where the formation of a secondary phase is displayed as a function of time at a given isothermal annealing temperature. Floreen et al., ${ }^{[17]}$ showed that $\delta$-phase is not expected to appear until after about 20 hours at $870{ }^{\circ} \mathrm{C}$ in homogenized, wrought IN625. They also showed that time required to initiate $\delta$-phase is reduced to times on the order of 1 hour in the vicinity of a weld. While the high cooling rates that occur during a typical welding operation are likely to produce locally inhomogeneous microstructures, the TTT diagrams constructed from these data do not capture the transformation kinetics that are produced during an AM build process. Suave et al. ${ }^{[6]}$ investigated the effect of processing on the precipitation of the $\delta$-phase in IN625 and showed that the strain energy associated with mechanical deformation also increased the precipitation kinetics. As such, data that account for the extreme metallurgical conditions produced during L-PBF (i.e., the repetitive thermal cycling, and orders of magnitude faster cooling rates) are essential to develop effective annealing treatments, as well as improved predictions of microstructure evolution and performance for in-service conditions.

This study presents a TTT diagram that was constructed for the as-built IN625 produced using L-PBF. Since the literature indicates that the as-built microstructure of AM-produced IN625 is strongly influenced by the type of AM process used, ${ }^{[5,18,19]}$ this study was limited to the microstructures produced by L-PBF. The investigation included isothermal annealing times up to 168 hours, and temperatures ranging from $650{ }^{\circ} \mathrm{C}$ to $1050{ }^{\circ} \mathrm{C}$. Both laboratory X-ray diffraction (XRD) and scanning electron microscopy (SEM) were used to determine the presence of the $\delta$-phase. The phase fraction of $\delta$-phase was estimated through analyses of the SEM images for each temperature/time combination. Details of the phase transformation kinetics were examined using CALPHAD-based thermodynamic modeling. ${ }^{[20]}$ In addition, synchrotron X-ray measurements using the ultra-small-angle X-ray scattering (USAXS) facility at the Advanced Photon Source (APS) at Argonne National Laboratory were used to provide quantitative in situ measurements of $\delta$-phase growth as a function of time during an isothermal anneal at $870{ }^{\circ} \mathrm{C}$. Finally, construction of an AM-based TTT diagram enables the design of alternative stress-relief heat treatments for AM-built IN625 that practically eliminates the formation of $\delta$-phase.

\section{EXPERIMENTAL PROCEDURE}

Fifteen millimeter cubes were additively built from virgin IN625 powder using an EOS* M270 L-PBF

*Certain commercial entities, equipment, or materials may be identified in this document to describe an experimental procedure or concept adequately. Such identification is not intended to imply recommendation or endorsement by the National Institute of Standards and Technology, nor is it intended to imply that the entities, materials, or equipment are necessarily the best available for the purpose.

system for this analysis. A standard EOS parameter set consisting of a laser power of $195 \mathrm{~W}$, a scan speed of 800 $\mathrm{mm} \mathrm{s}^{-1}$, a nominal powder layer thickness of $20 \mu \mathrm{m}$, and a hatch spacing of $100 \mu \mathrm{m}$, was used for the build. Variations in the as-built (AB) microstructure were reduced by adopting an "all-core" pattern in which the laser scans at the external surfaces were identical to those in the interior of the cubes. The cubes were cut from the build plate via electro-discharge machining $(\mathrm{EDM})$ in the as-built condition. Since the intent of this study was to evaluate the growth of $\delta$-phase, these specimens did not undergo any stress-relief heat treatment after the build was completed. The AB cubes were quartered and sealed in quartz ampules for heat treatment.

The encapsulated samples were annealed at temperatures ranging from $650{ }^{\circ} \mathrm{C}$ to $1050{ }^{\circ} \mathrm{C}$ and for times from 0.25 to 168 hours to evaluate the development of the $\delta$-phase. Portions of the heat-treated specimens were mounted and prepared for microstructural analysis using standard metallographic techniques and etched with aqua regia for examination in a scanning electron microscope (SEM). ${ }^{[21,22]}$

Laboratory-based X-ray diffraction (XRD) measurements were performed on the annealed samples using $\mathrm{Cu}$ $\mathrm{K} \alpha$ radiation. Initial $2 \theta$ scans were conducted over a range of $20 \mathrm{deg}$ to $100 \mathrm{deg} 2 \theta$ to identify the phases present in the samples. A second, more focused $2 \theta$ scan was then conducted from $30 \mathrm{deg}$ to $60 \mathrm{deg} 2 \theta$ to evaluate the relative intensities for the $\delta$-phase peaks. Additional in situ synchrotron scattering and diffraction experiments were conducted at the ultra-small-angle X-ray scattering (USAXS) facility at the Advanced Photon Source, Argonne National Laboratory to evaluate the incipient $\delta$-phase growth in the AM-IN625 at $870{ }^{\circ} \mathrm{C}$. This technique combines in situ USAXS, small angle $\mathrm{X}$-ray scattering, and XRD in the hard X-ray regime ${ }^{[23,24]}$ and it can reveal details about precipitation kinetics, including the simultaneous changes in morphology and atomic structure of precipitate phases. ${ }^{[25]}$ The X-ray energy for these measurements was $21 \mathrm{keV}$, and the X-ray flux was $10^{13}$ photon $/ \mathrm{s} / \mathrm{mm}^{2}$.

The presence of the $\delta$-phase was also determined by energy-dispersive X-ray spectroscopy (EDS). As shown previously, the resolution of the EDS measurements can be enhanced by performing them on a strain-free surface. ${ }^{[13]}$ Strain-free surfaces were produced with a vibrational polishing system with $0.02 \mu \mathrm{m}$ colloidal silica for a minimum of 4 hours. 
The $\delta$-phase fraction was estimated for each temperature/time combination through analyses of the SEM images. Automated binary (i.e., white or black) thresholding was performed on representative SEM images using a MATLAB ${ }^{[26]}$ script and Ostu's algorithm..$^{27]}$ The thresholding was optimized by reducing digital noise in the binary images with ImageJ. ${ }^{[28]}$ In some cases, the contrast between the $\delta$-phase and the matrix could not be easily separated and automated thresholding did not produce meaningful results. The phase fraction of the $\delta$-phase in these images was determined manually using a grid-intercept method. Since the matrix material was preferentially etched with respect to the $\delta$-phase precipitates, using the observed area fractions to estimate volume fractions can only be correct if the precipitates are all perpendicular to the sample surface. Since this is an incorrect assumption, these measurements overestimate the $\delta$-phase volume fraction, and for this reason, should be viewed as an upper bound value.

A variety of phase diagram sections and constrained equilibrium calculations were predicted using ThermoCalc $2017 \mathrm{a}^{[29]}$ and the ThermoCalc TCNI8 thermodynamic database. ${ }^{[30]}$ Specifically, the calculations were performed for the nominal powder composition and for an inter-dendritic-rich composition at a location $10 \mathrm{~nm}$ from the center of the inter-dendrite region as predicted by Keller et al. ${ }^{[11]}$ The calculations predicted the equilibrium volume fractions for the MC and $\delta$ phases, as well as the precipitation driving forces for a metastable MC or $\delta$ phase. The precipitation driving forces by definition were calculated as the Gibbs energy difference between a homogenous FCC matrix and a metastable precipitate phase (either MC carbide or $\delta$ phase).

\section{RESULTS AND DISCUSSION}

Figure 1 shows an $\mathrm{Nb}$-isopleth section for the nominal IN625 powder composition. The dashed line in the figure indicates the nominal 0.037 mass fraction of $\mathrm{Nb}$ in this alloy. The isopleth indicates that the $\delta$-phase $\left(\mathrm{Ni}_{3} \mathrm{Nb}\right)$ is thermodynamically stable over a wide range of temperatures for the nominal composition (i.e., from approximately $600{ }^{\circ} \mathrm{C}$ to $1000^{\circ} \mathrm{C}$ ) and that other phases, such as carbides, and $\sigma$-phase could also form during a stress-relief heat treatment at $870{ }^{\circ} \mathrm{C}$. Note that $\mathrm{Nb}$-isopleth displayed in Figure 1 predicts the equilibrium phases that could be present assuming a homogeneous composition (i.e., no micro-segregation) for a range from 2 to 6 mass pct $\mathrm{Nb}$. However, recent measurements showed that the local $\mathrm{Nb}$ and $\mathrm{Mo}$ concentrations in the inter-dendritic regions can be as high as 9 and 11 pct, respectively. ${ }^{[31]}$ Such variations in local composition are likely to increase the local equilibrium fractions of the precipitate phases (i.e., the $\delta$ phase, and MC carbide). Recent DICTRA ${ }^{\circledR}$ simulations predicting the micro-segregation in the as-built part also showed significant segregation at the interdenritic region. Predicted compositions from the inter-dendritic region and from the dendrite core are provided in

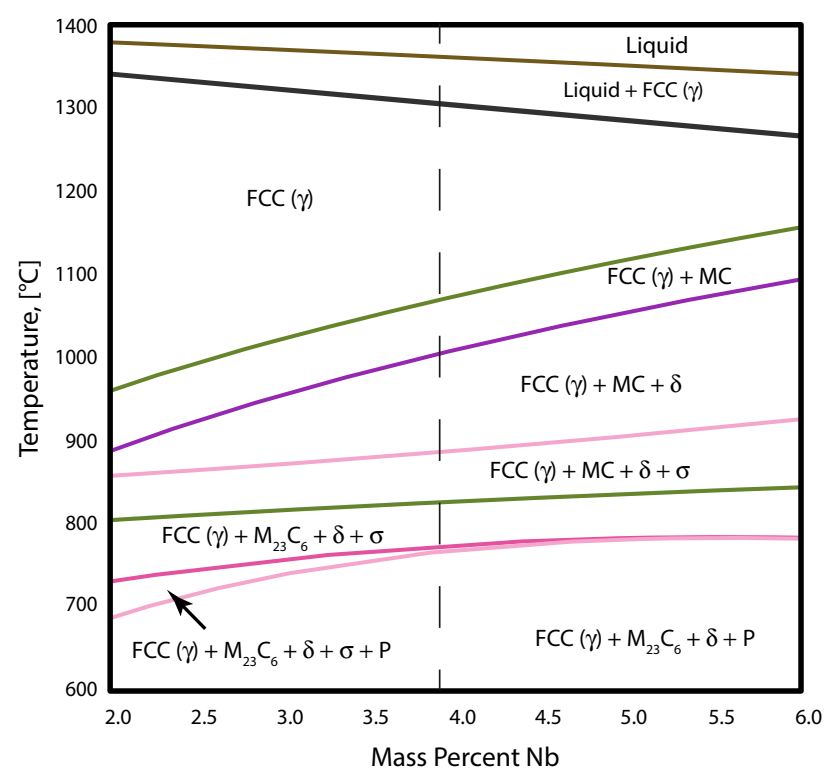

Fig. 1-An isopleth section of the IN625 phase diagram constructed from the powder composition shown in Table I. The dashed line indicates the $\mathrm{Nb}$ content in the virgin powder.

Table I. As expected, the predicted dendritic core composition is depleted in $\mathrm{Nb}$ and $\mathrm{Mo}$.

The SEM images in Figure 2 were obtained from polished and etched surfaces after four different annealing times at $870{ }^{\circ} \mathrm{C}$ and show the rate of $\delta$-phase growth in the XZ plane (i.e., parallel to the build direction) at that temperature. While the overall microstructure after 0.25 hours (Figure 2(a)) retained the dendritic as-built structure, fine $\delta$-phase plates were present along several inter-dendritic regions (shown at the arrows in the figure). EDS analyses confirmed that the dendrite cores (the darker regions) are enriched in $\mathrm{Ni}$ and $\mathrm{Cr}$, and that the inter-dendritic regions (the brighter regions) are higher in the solute elements of $\mathrm{Nb}$ and Mo. As such, the nucleation of $\delta$-phase plates favored the inter-dendritic regions where the local $\mathrm{Nb}$ concentrations were higher. Figure 2(b) reveals that the phase fraction of $\delta$-phase plates increased after 0.5 hours at $870{ }^{\circ} \mathrm{C}$; however, the relative size of the plates does not appear to have changed appreciably with respect to those in Figure 2(a). After 1 hour (Figure 2(c)), both the size and phase fraction of the $\delta$-phase are noticeably increased and become even more prominent after 4 hours (Figure 2(d)).

The XRD patterns obtained for the four times in Figure 2 are shown in Figure 3. All four patterns exhibit several distinct peaks in addition to the large FCC matrix peaks. Specifically, an additional peak is present at $40.8 \mathrm{deg} 2 \theta$, and a two-peak doublet is present near 46 $\operatorname{deg} 2 \theta$. These peaks are the $\delta\{201\}, \delta\{012\}$, and $\delta\{211\}$ peaks (respectively) associated with the orthorhombic $\mathrm{Ni}_{3} \mathrm{Nb} \delta$-phase and, like the micrographs in Figure 2, they all increased progressively as a function of time, indicating an increase of the volume fraction of the $\delta$ phase. ${ }^{[32]}$

Figure 4 shows the nature of $\delta$-phase growth in the $\mathrm{XZ}$ plane after a 1-hour annealing heat treatment at 
Table I. Composition of the IN625 Powder Feedstock Used to Produce the AM Parts Investigated in the Present Study

\begin{tabular}{lcccc}
\hline & \multicolumn{2}{c}{ Nominal } & & \\
Element & $\begin{array}{c}\text { Composition (Mass } \\
\text { Percent) }\end{array}$ & $\begin{array}{c}\text { Composition (Atomic } \\
\text { Percent) }\end{array}$ & $\begin{array}{c}\text { Inter-Dendritic Region } \\
\text { Composition (Mass } \\
\text { Percent) }\end{array}$ & $\begin{array}{c}\text { Dendrite Core }^{\mathrm{a}} \\
\text { Composition (Mass } \\
\text { Percent) }\end{array}$ \\
\hline $\mathrm{Ni}$ & balance & 65.99 & balance & balance \\
$\mathrm{Cr}$ & 20.70 & 23.73 & 20.2 & 7.0 \\
$\mathrm{Mo}$ & 8.83 & 5.49 & 8.7 & 2.0 \\
$\mathrm{Nb}$ & 3.79 & 2.43 & 0.6 & 0.72 \\
$\mathrm{Fe}$ & 0.72 & 0.77 & & \\
$\mathrm{Ti}$ & 0.35 & 0.44 & & 0.005 \\
$\mathrm{Al}$ & 0.28 & 0.62 & & 0.01 \\
$\mathrm{Co}$ & 0.18 & 0.18 & & \\
$\mathrm{Mn}$ & 0.03 & 0.03 & & \\
$\mathrm{C}$ & 0.01 & 0.05 & & \\
$\mathrm{Si}$ & 0.13 & 0.28 & & \\
$\mathrm{P}$ & $<0.01$ & & & \\
$\mathrm{~S}$ & $<0.01$ & & & \\
\hline
\end{tabular}

The uncertainties in the nominal values are within the limits specified by ASTM E1621 and ASTM E1019 $9^{[38,39]}$

${ }^{a}$ Calculations based on DICTRA simulations performed by Keller et al. ${ }^{[11]}$
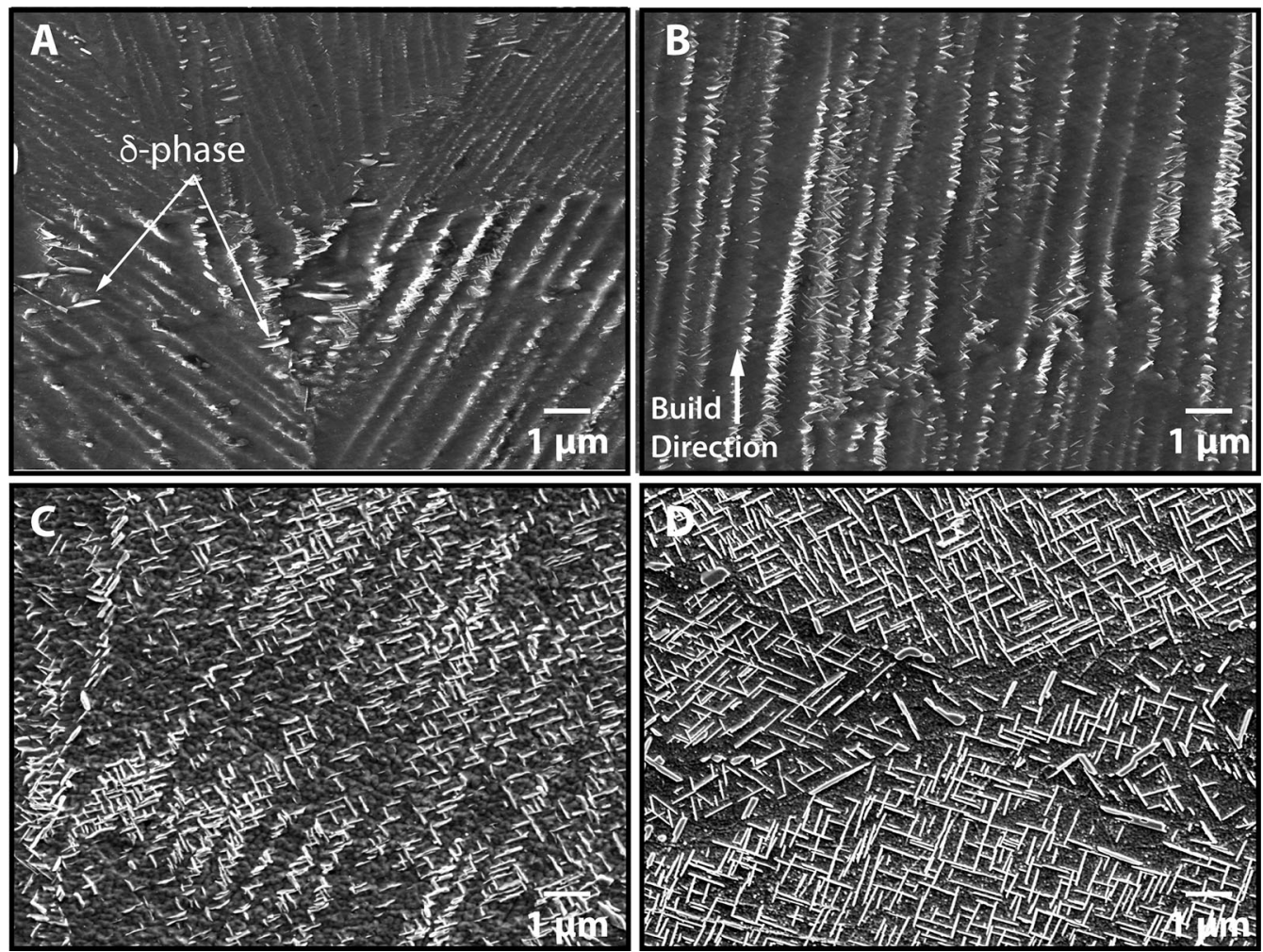

Fig. 2-The formation and growth of $\delta$-phase plates in additively-manufactured IN 625 after four different annealing times at $870{ }^{\circ} \mathrm{C}$. $(a)$ After $0.25 \mathrm{~h},(b)$ after $0.5 \mathrm{~h},(c)$ after $1 \mathrm{~h}$, and $(d)$ after $4 \mathrm{~h}$ at $870{ }^{\circ} \mathrm{C}$.

four different temperatures. After 1 hour at $700{ }^{\circ} \mathrm{C}$ (Figure 4(a)), the microstructure is essentially the same as that observed in the as-built condition. After 1 hours at $800{ }^{\circ} \mathrm{C}$ (Figure $4(\mathrm{~b})$ ), some fine $\delta$-phase plates are visible along several inter-dendritic regions (denoted by the arrows in the figure). Note that the area fraction of $\delta$-phase after 1 hour at $800{ }^{\circ} \mathrm{C}$ is considerably smaller than that shown for the 0.25 and 0.5 hours at $870{ }^{\circ} \mathrm{C}$ in Figure 2. Figure 4(c) shows the microstructure after the manufacturer-recommended stress-relaxation heat treatment of 1 hour at $870{ }^{\circ} \mathrm{C}$. The image in Figure 4(c) was taken from a different region of the same surface shown in Figure 2(c), and even though the overall surface exhibits a significant fraction of $\delta$-phase after this heat treatment, the differences between these two figures indicate that the $\delta$-phase is not uniformly distributed over the surface. That is, both the orientation of the solidification fronts, and the conditions within the 
dendrites (e.g., localized variations in solidification rate, composition, and magnitude of residual stresses) appear to influence the nucleation and growth of $\delta$-phase platelets. Figure 4(d) shows that the phase fraction of

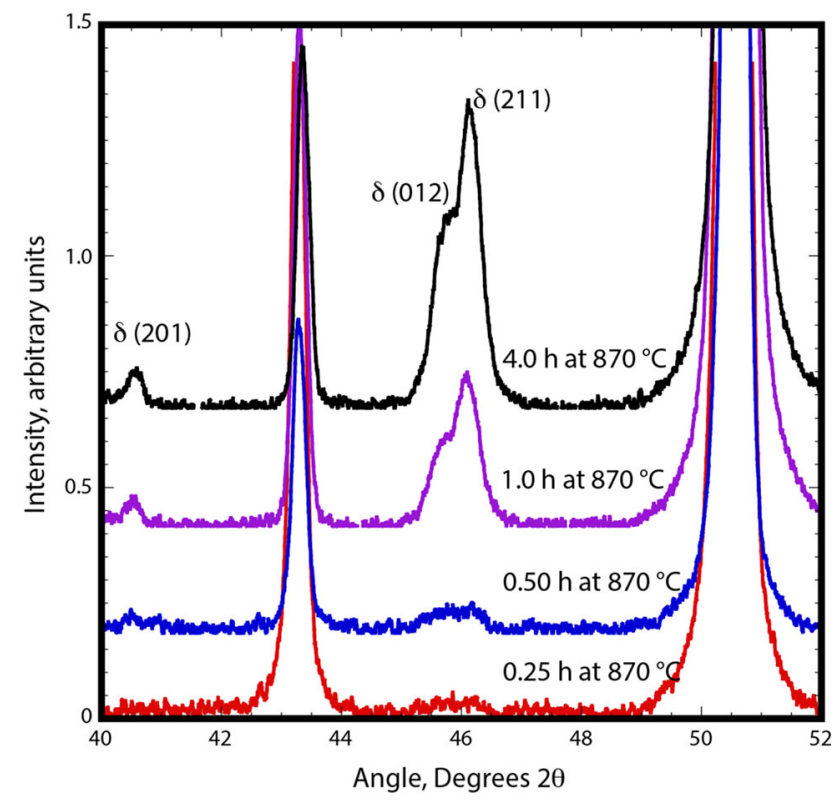

Fig. 3-XRD patterns for the four times at $870{ }^{\circ} \mathrm{C}$ shown in Fig. 3 . The patterns reveal a progressive increase in the magnitude of the peak located at $40.8 \mathrm{deg} 2 \theta$, as well as the two-peak doublet near 46 deg $2 \theta$ with time. These peaks are associated with the orthorhombic $\mathrm{Ni} 3 \mathrm{Nb} \delta$-phase. the plates is significantly reduced after 1 hour at $950{ }^{\circ} \mathrm{C}$ as compared to $870{ }^{\circ} \mathrm{C}$. In addition, the difference in the overall character of the microstructure in Figure 4(d) with respect to the as-built dendritic microstructure in Figure 4(a) suggests that this sample was in the early stages of homogenization.

The XRD patterns corresponding to the four temperatures shown in Figure 4 are presented in Figure 5. The pattern acquired for 1 hour at $700{ }^{\circ} \mathrm{C}$ exhibits no identifiable peaks except for those of the FCC phase and is virtually identical to the pattern acquired for the as-built condition, i.e., that of an inhomogeneous single-phase FCC solid solution. Two small $\delta$-phase peaks were observed near $46 \mathrm{deg} 2 \theta$ in the pattern acquired after 1 hour at $800{ }^{\circ} \mathrm{C}$. The intensities of these peaks were considerably higher after 1 hour at $870{ }^{\circ} \mathrm{C}$. The XRD data after 1 hour at $950{ }^{\circ} \mathrm{C}$ also show these distinctive peaks, which confirms the presence of the $\delta$-phase; however, the intensity is substantially lower when compared to the pattern at $870{ }^{\circ} \mathrm{C}$. The $950{ }^{\circ} \mathrm{C}$ pattern also shows the presence of two small peaks near $42.5 \mathrm{deg}$ and at $44.5 \mathrm{deg}$, which were determined to be produced by $\mathrm{MC}$ matrix carbides i.e., $(\mathrm{Nb}, \mathrm{Mo}) \mathrm{C}$. There are two processes occurring that influence the precipitation process at temperatures greater than $900{ }^{\circ} \mathrm{C}$. First, the system is beginning to homogenize more rapidly, and the composition gradients are decreasing and moving toward the nominal powder composition. This process promotes the formation of the MC carbide and dissolution of the $\delta$ phase. At $950{ }^{\circ} \mathrm{C}$, Table II shows that the predicted equilibrium volume fraction for
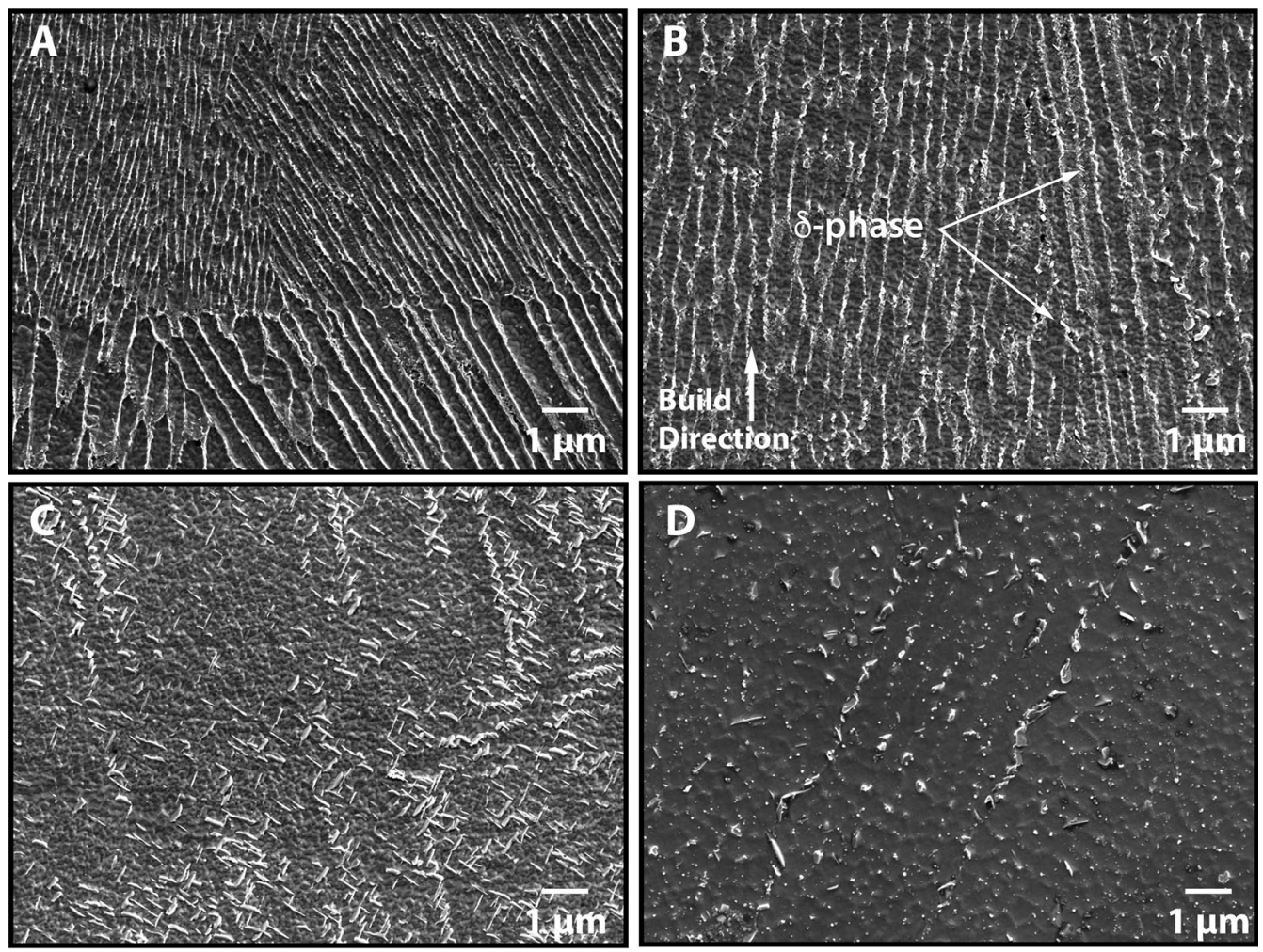

Fig. 4-The formation and growth of $\delta$-phase in additively-manufactured IN 625 after a 1-h annealing heat treatment at four different temperatures. (a) At $700{ }^{\circ} \mathrm{C},(b)$ at $800{ }^{\circ} \mathrm{C},(c)$ at $870{ }^{\circ} \mathrm{C}$, and $(d)$ at $950{ }^{\circ} \mathrm{C}$. 
the $\delta$ phase for inter-dendritic composition is $17.9 \mathrm{pct}$ and that it is zero in the nominal powder composition. Thus, the overall fraction of the $\delta$ phase decreases as homogenization occurs. Concurrently, at the higher temperatures, the $\mathrm{MC}$ carbide appears as an equilibrium phase, although it has a very small equilibrium volume fraction $(0.005$ for the inter-dendritic region and 0.0005 for the nominal powder composition). These low volume fractions are based on assumptions that the carbon content in the inter-dendritic region is 0.005 mass pct, while the reported carbon content is 0.01 mass pct in the powder. As reported by Silva and Cieslak, ${ }^{[33,34]}$ the actual carbon concentration may be higher, which promotes the formation of the MC carbide over the $\delta$ phase. In addition, localized variations in the carbon content could also occur and small increases in the carbon content ( $>0.04$ mass pct $C$ ) would likely

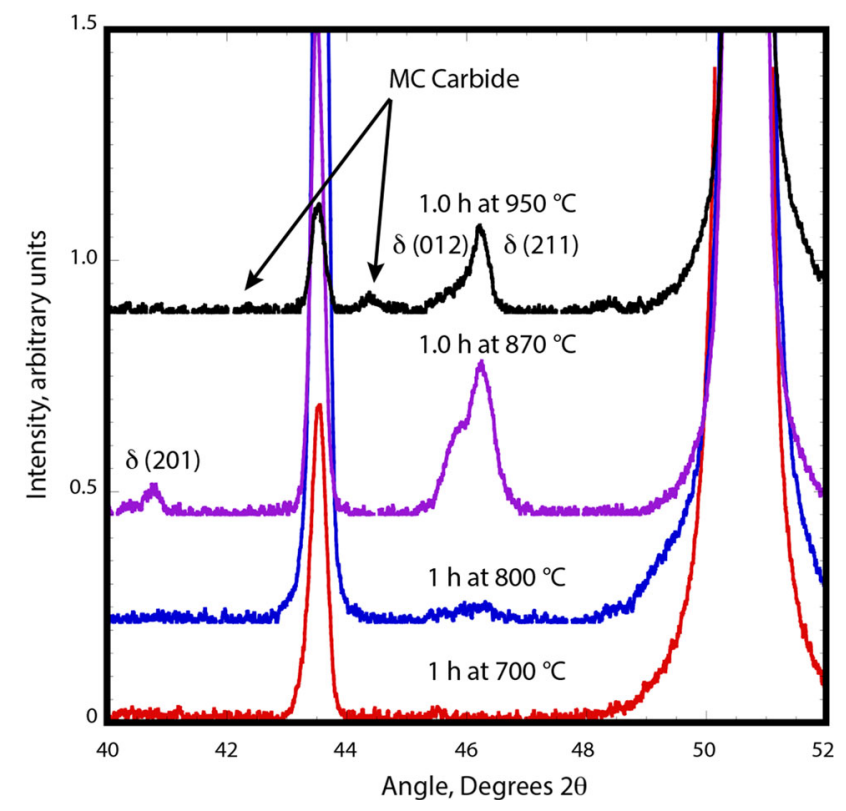

Fig. 5-XRD patterns for the four temperatures shown in Fig. 4. The patterns reveal changes in the magnitude of the two-peak doublet located near $46 \mathrm{deg} 2 \theta$. These peaks are associated with the orthorhombic Ni3Nb $\delta$-phase. The peaks near $42.52 \theta$ and $44.52 \theta$ in the $950{ }^{\circ} \mathrm{C}$ pattern indicate the presence of matrix carbides. promote the formation of the MC carbide over the $\delta$-phase during solidification. As shown in Table II, the MC carbide precipitation driving force is seven times higher than the driving force for the $\delta$ phase in the inter-dendritic-rich composition at $950{ }^{\circ} \mathrm{C}$. When combined with a local increase in carbon content, the higher precipitation driving force would promote the formation of the MC carbides. Note that an additional higher temperature phase, $\gamma$ ", has been observed in the AM-IN625. ${ }^{[13]}$ Both the $\gamma^{\prime \prime}$ and $\delta$-phases are based on the intermetallic composition $\mathrm{Ni}_{3} \mathrm{Nb}$, but they feature differing stacking sequences of atomically dense planes and differing atomic arrangements of the $\mathrm{Ni}$ and $\mathrm{Nb}$ atoms on those planes. ${ }^{[35]}$ Since differentiation of these two phases requires detailed analyses in the TEM only the formation of the $\delta$-phase is considered in this work. The formation kinetics of $\gamma$ " in AM-IN625 are the subject of a different investigation. ${ }^{[36]}$

The $\delta$-phase volume fraction was estimated for each sample using the SEM-based analyses described above. By themselves, these determinations could only be considered upper bounds since the measured area fractions of these etched surfaces can significantly overestimate the true volume fractions. To overcome this limitation, large-volume synchrotron X-ray diffraction measurements were performed on an AM-IN625 specimen annealed at $870{ }^{\circ} \mathrm{C}$ for 8 hours. The integrated $\delta$-phase and fcc matrix peak intensities demonstrated that the $\delta$-phase volume fraction was approximately 5.4 pct, which is consistent with the estimated equilibrium volume faction of 4.1 pct shown in Table II. The synchrotron measurement result was then used to calculate a normalization factor for the SEM-based area-fraction measurements.

The resulting normalized volume fraction of $\delta$-phase is presented in Figure 6 as a function of annealing time at $800{ }^{\circ} \mathrm{C}$ and at $870{ }^{\circ} \mathrm{C}$. The error bars associated with each data point represent an estimated uncertainty of 15 pct. Dashed lines were placed between the data points in Figure 6 to illustrate the differences in the growth rates of the $\delta$-phase at the two temperatures. Initially, the growth rate of the $\delta$-phase at $870{ }^{\circ} \mathrm{C}$ was faster than that at $800{ }^{\circ} \mathrm{C}$; however, with time, the volume fraction of $\delta$-phase at $800{ }^{\circ} \mathrm{C}$ surpassed that at $870{ }^{\circ} \mathrm{C}$ with the crossover point occurring between 13 and 14 hours. This

Table II. Comparison of MC and d Phase Precipitation Driving Forces and Equilibrium Fractions for the Nominal Composition and Inter-dendritic-Rich Composition as a Function of Temperature

\begin{tabular}{|c|c|c|c|c|c|c|c|c|}
\hline \multirow[b]{2}{*}{$\begin{array}{l}\text { Temperature } \\
\left({ }^{\circ} \mathrm{C}\right)\end{array}$} & \multicolumn{4}{|c|}{ Inter-dendritic Rich (10 nm from Edge) } & \multicolumn{4}{|c|}{ Nominal Composition } \\
\hline & $\begin{array}{c}\text { Volume } \\
\text { Fraction } \\
\quad \delta \\
\end{array}$ & $\begin{array}{l}\text { Volume } \\
\text { Fraction } \\
\text { MC }\end{array}$ & $\begin{array}{l}\text { Driving Force } \\
\text { for } \delta(\mathrm{J} / \mathrm{mol})\end{array}$ & $\begin{array}{c}\text { Driving Force } \\
\text { for } \mathrm{MC} \\
(\mathrm{J} / \mathrm{mol})\end{array}$ & $\begin{array}{c}\text { Volume } \\
\text { Fraction } \\
\delta \\
\end{array}$ & $\begin{array}{l}\text { Volume } \\
\text { Fraction } \\
\text { MC }\end{array}$ & $\begin{array}{l}\text { Driving } \\
\text { Force for } \delta \\
(\mathrm{J} / \mathrm{mol})\end{array}$ & $\begin{array}{c}\text { Driving Force } \\
\text { for MC } \\
(\mathrm{J} / \mathrm{mol}) \\
\end{array}$ \\
\hline 700 & 24.4 & 0 & 4757 & 18,657 & 8.62 & 0 & 2880 & 9299 \\
\hline 750 & 24.1 & 0 & 4193 & 15,937 & 7.71 & 0 & 2275 & 7936 \\
\hline 800 & 23.2 & 0 & 3641 & 15,037 & 6.41 & 0.06 & 1680 & 6575 \\
\hline 870 & 20.6 & 0 & 2875 & 15,577 & 4.11 & 0.053 & 867 & 4676 \\
\hline 900 & 19.6 & 0.49 & 2551 & 15,000 & 2.55 & 0.05 & 527 & 3864 \\
\hline 950 & 17.9 & 0.49 & 2018 & 14,100 & 0 & 0.04 & 0 & 2513 \\
\hline
\end{tabular}




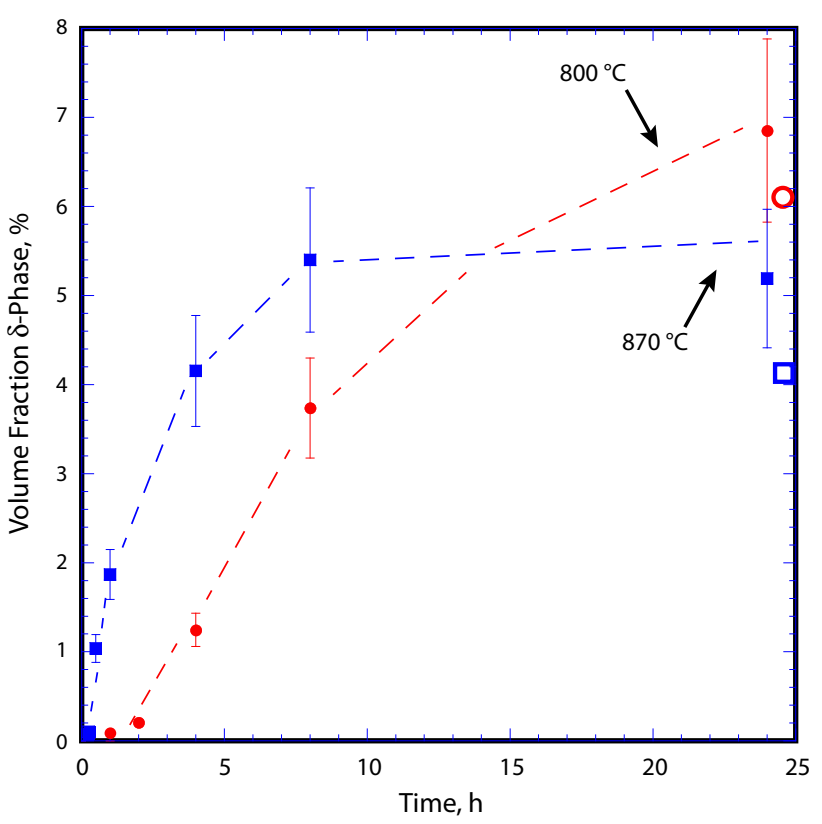

Fig. 6-The estimated volume fraction ratio of $\delta$-phase presented as a function of annealing time at $800{ }^{\circ} \mathrm{C}$ and at $870{ }^{\circ} \mathrm{C}$. The open plot symbols represent the volume fraction ratios predicted after $100 \mathrm{~h}$ $\left(6.41\right.$ pet at $800{ }^{\circ} \mathrm{C}$ and 4.11 pet at $870{ }^{\circ} \mathrm{C}$ ). The error bars associated with each data point represent an estimated 15 pct uncertainty.

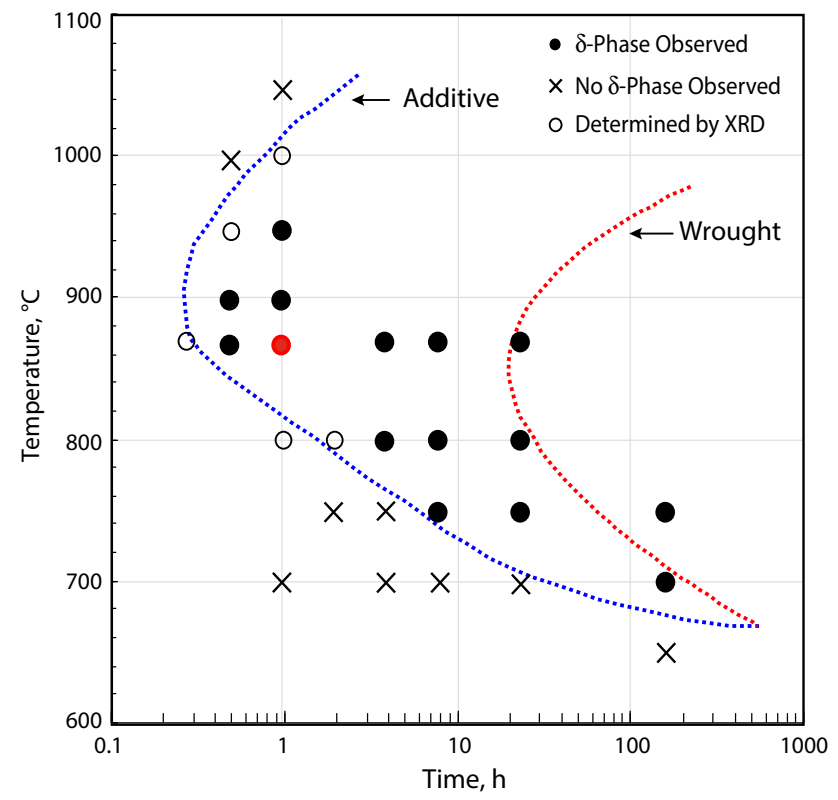

Fig. 7-A time-temperature-transformation (TTT) diagram comparing the presence of $\delta$-phase in additively-manufactured IN625 to the wrought material (from Ref. 17). The dashed lines estimate approximately 1 pct volume fraction of $\delta$-phase.

behavior is consistent with the equilibrium volume fractions predicted for long heat treatments at $800 \mathrm{deg}$ and at $870{ }^{\circ} \mathrm{C}$, which show a larger terminal volume fraction of $\delta$-phase at the lower temperature; the equilibrium predictions are denoted as open plot symbols in the figure. These equilibrium predictions are also

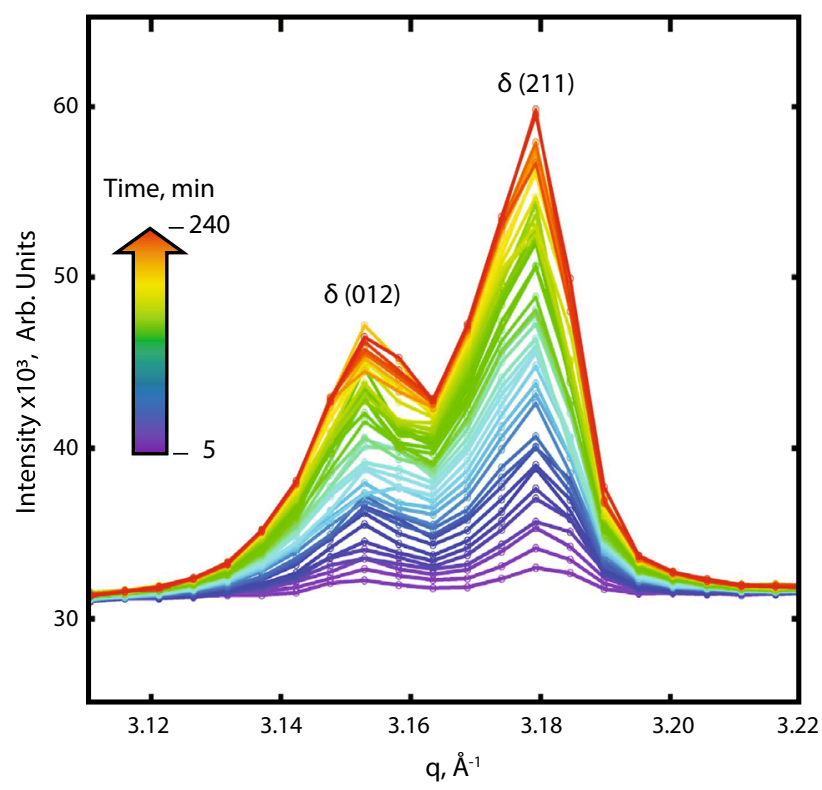

Fig. 8-The intensity increase for two closely located $\delta$-phase peaks during a 4-h annealing heat treatment at $870{ }^{\circ} \mathrm{C}$. The progression of time is illustrated by the color scale inside the arrow.

consistent with the measured volume fractions from the longest anneals (24 hours) at both temperatures.

The results from the analyses of the individual time/ temperature combinations were compiled to construct a conventional TTT curve, which is presented as Figure 7. The filled circles in the figure signify the time/temperature combinations where the presence of $\delta$-phase was distinct in the SEM images. Similarly, the open circles in the figure indicate a time/temperature combination where the presence of $\delta$-phase in the SEM images was inconclusive and required confirmation by XRD or by EDS analyses. The $X$ 's in the figure indicate the time/ temperature combinations where no $\delta$-phase was observed in the SEM images, or in either the XRD patterns, or in the EDS data. A dashed line was placed in the figure to separate the regions where the $\delta$-phase formation is expected and where the $\delta$-phase is not likely to form during heat treatment. Clearly, the location of the $\delta$-phase boundary is dependent on the sensitivity of the measurement method and, considering the resolution of the characterization techniques used in this study, a reasonable estimate for the lower detection limit would be approximately 1 pct volume fraction of $\delta$-phase. Consequently, the dashed line in Figure 7 represents the boundary where a minimum of 1 pct volume fraction of $\delta$-phase is present in this alloy. An assessment of the $\delta$-phase growth using a more sensitive measurement method could detect the presence of the $\delta$-phase at a significantly smaller volume fraction. As shown in Figure 8, time-resolved measurements of $\delta$-phase growth performed in situ with synchrotron $\mathrm{X}$-rays during an isothermal anneal at $870{ }^{\circ} \mathrm{C}$ (Figure 8) revealed the presence of distinct $\delta$-phase peaks after a 5-minute exposure at this temperature.

A line that assumes a similar volume fraction of $\delta$-phase, adapted from the work by Floreen et al. ${ }^{[17]}$ was 
included in Figure 7 to compare $\delta$-phase formation in an AM material to that in wrought IN625. The difference in the locations of two boundaries established that the time required to form $\delta$-phase in the additively-manufactured IN625 is at least two orders of magnitude less than that in wrought IN625 with a similar nominal composition. ${ }^{[17]}$ The observed shift in time to form $\delta$-phase was almost certainly due to the large local composition gradients produced by the rapid cooling and subsequent micro-segregation in the additive material. However, Suave et al., ${ }^{[6]}$ showed that variations in the local strain conditions can also produce a shift in the time for $\delta$-phase formation. The shift observed in AM-produced $\delta$-phase formation was approximately one order of magnitude faster than what was reported in deformed wrought IN625 sheet. Since the material in the vicinity of a weld often exhibits segregated microstructures and variations in local residual stresses, the magnitude of the shift observed for AM-produced $\delta$-phase formation was more consistent with that between welded and wrought IN625, as reported by Floreen et al. ${ }^{[17]}$

Recently published results indicate that the residual stresses in an as-built component can be severe and easily introduce substantial distortion in the AM components if they are not relaxed prior to the part being cut from the build plate. ${ }^{[13]}$ The magnitudes of these residual stresses have been shown to approach the yield stress in AM IN625, so the primary purpose of a 'low temperature' heat treatment is to relax these residual stresses so that AM components can be safely removed from the build plate. The red filled circle in Figure 7 illustrates the position of the industry-recommended stress-relief heat treatment (1 hours at $870{ }^{\circ} \mathrm{C}$ ) with respect to the boundary where at least 1 pct volume fraction of $\delta$-phase is present. This particular time/temperature combination lies well within the region where $\delta$-phase is expected to form and, according to Figure 6 , it produces a volume fraction of $\delta$-phase of approximately 2 pct. Lass et al., ${ }^{[13]}$ proposed that heat treating at a lower temperature, e.g., $800{ }^{\circ} \mathrm{C}$, could be a potential alternative stress-relief heat treatment option. Again, according to Figure 6, this time/ temperature combination produces less than 0.5 pct $\delta$-phase. Note that all of the specimens in this study had relatively uniform cross sections, which promoted homogeneous heating and cooling conditions. However, 'real' components are likely to feature both thick and thin cross sections, which will affect the homogeneity of the heat treatment. Local dissimilarities in the cooling rate will likely give rise to variability in the $\delta$-phase content in the component.

As stated above, $\delta$-phase is known to form in wrought IN625 after extended periods of time at elevated temperatures and can reduce the ductility and corrosion resistance of this alloy. ${ }^{[9]}$ Considering that some fraction of $\delta$-phase is likely to form during a stress-relief heat treatment, the shift in the $\delta$-phase boundary raises the following key question: Once it has formed, does the presence of $\delta$-phase alter the time required to fully homogenize the material? That is, how hard is it to completely remove $\delta$-phase once it has formed in an AM component? Zhang et al. ${ }^{[10]}$ concluded that 1 hour at $1150{ }^{\circ} \mathrm{C}$ sufficiently homogenizes the micro-segregation introduced by the L-PBF process in IN625, but the efficacy of this particular heat treatment protocol on the dissolution of $\delta$-phase is unclear at this time. Undoubtedly, limiting the initial amount of $\delta$-phase in a component would increase the likelihood that the $\delta$-phase would be removed during homogenization. While the relationship between heat treatment and the dissolution of $\delta$-phase is outside the scope of this study, additional studies designed to assess this relationship are in progress.

The fact that the shift in the boundary in Figure 7 denoting the region where $\delta$-phase is expected to form was dependent on the nominal $\mathrm{Nb}$ and Mo contents raises an additional key question: How sensitive is the position of the boundary to variations in the concentration of these two elements? That is, can the composition of AM-IN625 powder be optimized to control the $(\mathrm{Nb}, \mathrm{Mo})$ segregation that promotes the formation of $\delta$-phase? Even though the thermal conditions generated during the L-PBF process were a significant factor in the micro-segregation, little can be done to mitigate that influence. For this reason, modification of the powder composition designed to stabilize the $(\mathrm{Nb}, \mathrm{Mo})$ in the as-built condition appears to be a reasonable approach to reduce the formation of $\delta$ and other deleterious intermetallic phases in this alloy. Additional research examining the relative influence of $\mathrm{Nb}$ and Mo concentration variations on the kinetics of $\delta$-phase formation in AM-IN625 is also in progress. ${ }^{[36]}$

The sensitivity to variations in composition is an increasingly important issue considering that reusing powder has become a widely accepted industrial practice to reduce the costs associated with AM. The characteristics of the powder are known to affect the thermal processes during the L-PBF process, and this could produce unexpected variations in the material properties of a component. Studies performed on reused powder revealed that after multiple uses, the powder generally does not exhibit significant changes in particle size or shape with respect to virgin powder. However, some variabilities in the microstructure and composition were observed, which were attributed to changes in the concentration of some primary constituents (e.g., Ni, $\mathrm{Mn}$ and $\mathrm{Cu}) .^{[37]}$ An examination of the relationships between powder reuse, deleterious phase formation, and homogenization heat treatment in AM-IN625 is also planned.

The results of this study distinctly show that the segregated microstructure in the as-built material strongly influences the kinetics of $\delta$-phase formation in AM IN625 as compared to homogenized wrought material. Control of the $\delta$-phase is particularly important for reliable prediction of the performance-especially at elevated temperatures where the microstructural stability and the consistency of mechanical properties are more likely to be affected by the presence of $\delta$-phase. For this reason, thorough homogenization is strongly recommended prior to using any AM-produced IN625 component in service. 


\section{CONCLUSIONS}

This research evaluated the kinetics of $\delta$-phase growth in AM IN625 produced by L-PBF. The results of DICTRA simulations, revealed that the segregation generated by the L-PBF process promotes localized concentrations of $\mathrm{Nb}$ and $\mathrm{Mo}$ as high as 9 and 11 pct, respectively, in the inter-dendritic regions, which differ substantially from the bulk powder composition. Scanning electron microscopy confirmed that initiation of $\delta$-phase platelets favored the higher concentrations of $\mathrm{Nb}$ in the inter-dendritic regions. The SEM analyses also established that the $\delta$-phase was not uniformly distributed over the surface. That is, both the orientation of the solidification fronts and the conditions within the dendrites (e.g., localized variations in solidification rate, composition, and magnitude of residual stresses), had a strong influence on the growth of the $\delta$-phase platelets. At $870{ }^{\circ} \mathrm{C}$, the driving force to form $\delta$-phase was such that 5 minutes at this temperature produced enough $\delta$-phase that it was detectable in synchrotron X-ray spectra. After 15 minutes, the $\delta$-phase had grown to where it was visible in the SEM images and was measurable by XRD.

A conventional TTT curve was constructed from time/temperature data compiled from temperatures ranging between $650{ }^{\circ} \mathrm{C}$ and $1050{ }^{\circ} \mathrm{C}$, and times from 0.25 to 168 hours. Compared to the growth kinetics in wrought IN625 with similar composition, the formation of $\delta$-phase occurred at least two orders of magnitude faster in the AM IN625. The shift in the time was attributed to the large local composition gradients produced during the repetitive rapid thermal transients and ensuing micro-segregation in the additive material.

The TTT curve also revealed that the industry-recommended stress-relief heat treatment (1 hour at $\left.870{ }^{\circ} \mathrm{C}\right)$ lies well within the region where $\delta$-phase is observed. A plot of the $\delta$-phase growth kinetics in this material indicated that this time/temperature combination produces approximately 2 pct volume fraction of $\delta$-phase, whereas performing a stress-relief heat treatment at $800^{\circ} \mathrm{C}$ produces less than 0.5 pct $\delta$-phase. Considering that real specimens are likely to include both thick and thin sections, which are likely to have different local cooling rates that promote variability in the $\delta$-phase content, avoiding heat treatments that promote the formation of $\delta$-phase in AM components that are not homogenized is highly recommended.

The results of this study revealed that the segregated microstructure in the as-built material strongly influences the kinetics of $\delta$-phase formation in AM IN625. As such, control of the $\delta$-phase and other deleterious intermetallic phases is essential to enable reliable prediction of the performance of components in service. Several approaches are available for this purpose including modifying the powder composition to stabilize the $\mathrm{Nb}$ and Mo segregation in the as-built condition. Since powder reuse has become a widely accepted industrial practice, minimizing the influence of variations in $\mathrm{Nb}$ and Mo content on the formation of $\delta$-phase will become increasingly more significant. This will be particularly true at elevated temperatures where the microstructural stability and the consistency of mechanical properties are more likely to be affected by the presence of the $\delta$ and other deleterious phases.

\section{ACKNOWLEDGMENTS}

The authors would like to thank Dr. T.Q. Phan, Dr. G. Jacob, and Dr. C.U. Brown the NIST Engineering Laboratory for supplying the material used in this study. The authors would also like to thank Dr. S.Y. Lee for his input and assistance with the development of the image analyses algorithms, and Ms. S.A. Claggett for her invaluable assistance with the metallography. The use of the Advanced Photon Source, an Office of Science User Facility operated for the U.S. Department of Energy (DOE) Office of Science by Argonne National Laboratory, was supported by the U.S. DOE under Contract No. DE-AC02-06CH11357.

\section{REFERENCES}

1. S.S. Babu, L. Love, R. Dehoff, W. Peter, T.R. Watkins, and S. Pannala: MRS Bull, 2015, vol. 40, pp. 1154-61.

2. W.E. Frazier: J. Mater. Eng. Perform., 2014, vol. 23, pp. 1917-28.

3. D.D. $\mathrm{Gu}, \mathrm{W}$. Meiners, K. Wissenbach, and R. Poprawe: Int. Mater. Rev., 2013, vol. 57, pp. 133-64.

4. G.K. Dey, S. Albert, D. Srivastava, M. Sundararaman, and P. Mukhopadhyay: Mater. Sci. Eng. A, 1989, vol. 119, pp. 175-84.

5. G.P. Dinda, A.K. Dasgupta, and J. Mazumder: Mater. Sci. Eng. $A, 2009$, vol. 509, pp. 98-104.

6. L. Suave, J. Cormier, P. Villechaise, A. Soula, Z. Hervier, D. Bertheau, and J. Laigo: Metall. Mater. Trans. A, 2014, vol. 45A, pp. 2963-82.

7. P. Petrzak, K. Kowalski, and M. Blicharski: Acta Phys. Pol. A, 2016, vol. 130, pp. 1041-44.

8. M. Sundararaman, L. Kumar, G.E. Prasad, P. Mukhopadhyay, and S. Banerjee: Metall. Mater. Trans. A, 1999, vol. 30A, pp. 41-52.

9. F. Cortial, J.M. Corrieu, and C. Vernot-Loier: Metall. Mater. Trans. A, 1995, vol. 26A, pp. 1273-86.

10. F. Zhang, L.E. Levine, A.J. Allen, C.E. Campbell, E.A. Lass, S. Cheruvathur, M.R. Stoudt, M.E. Williams, and Y. Idell: Scripta Mater., 2017, vol. 131, pp. 98-102.

11. T. Keller, G. Lindwall, S. Ghosh, L. Ma, B.M. Lane, F. Zhang, U.R. Kattner, E.A. Lass, J.C. Heigel, Y. Idell, M.E. Williams, A.J. Allen, J.E. Guyer, and L.E. Levine: Acta Mater., 2017, vol. 139, pp. 244-53.

12. S. Ghosh, M.R. Stoudt, L.E. Levine and J.E. Guyer, Scripta Mater. 2017.

13. E.A. Lass, M.R. Stoudt, M.E. Williams, M.B. Katz, L.E. Levine, T.Q. Phan, T.H. Gnaeupel-Herold, and D.S. Ng: Metall. Mater. Trans. A, 2017, vol. 48A, pp. 5547-58.

14. J. Mittra, S. Banerjee, R. Tewari, and G.K. Dey: Mater. Sci. Eng. $A$, 2013, vol. 574A, pp. 86-93.

15. V. Shankar, K.B. Rao, and S.L. Mannan: J. Nucl. Mater., 2001, vol. 288 , pp. 222-32.

16. M. Sundararaman, P. Mukhopadhyay, and S. Banerjee: Metall. Trans. A, 1988, vol. 19, pp. 453-65.

17. S. Floreen, G.E. Fuchs and W.J. Yang, In Superalloys 718, 625, 706 and Various Derivatives, ed. E. A Loria (TMS: Warrendale, PA, 1994), pp. 13-37.

18. A. Mostafaei, Y. Behnamian, Y.L. Krimer, E.L. Stevens, and J.L. Luo: Mater. Des., 2016, vol. 111, pp. 482-91.

19. L.E. Murr, E. Martinez, S.M. Gaytan, D.A. Ramirez, B.I. Machado, P.W. Shindo, J.L. Martinez, F. Medina, J. Wooten, D. Ciscel, U. Ackelid, and R.B. Wicker: Metall. Mater. Trans. A, 2011, vol. 42A, pp. 3491-3508. 
20. N. Saunders and A.P. Miodownik: Pergamon, Oxford, New York, 1998, p. 479.

21. G.F. VanderVoort: Metallography Principles and Practice, ASM International, Materials Park, OH, 1999.

22. Anon: ASM Handbook: Metallography and Microstructures, 9th ed., vol., 9, ASM International, Metals Park, OH, 1985.

23. J. Ilavsky, P.R. Jemian, A.J. Allen, F. Zhang, L.E. Levine, and G.G. Long: J. Appl. Crystal., 2009, vol. 42, pp. 469-79.

24. J. Ilavsky, F. Zhang, A.A. Allen, L.E. Levine, P. Jemian, and G.G. Long: Metall. Mater. Trans. A, 2013, vol. 44A, pp. 68-76.

25. F. Zhang, L.E. Levine, A.J. Allen, C.E. Campbell, A.A. Creuziger, N. Kazantseva, and J. Ilavsky: Acta Mater., 2016, vol. 111, pp. 385-98.

26. The MathWorks Inc.: Matlab®, Natick, MA, 2016.

27. Anon: Otsu's_Method, Wikipedia, The Free Encyclopedia., 2017. https:/en. wikipedia.org/w/index.php?title $=$ Otsu\%27s_method\&oldid $=793353425$.

28. U. S. National Institutes of Health, Imagej64, Bethesda, MD, 1997-2016.

29. Thermo-Calc Software AB, Thermo-Calc, Stockholm, Sweden, 2017.

30. Themo-Calc Software AB, Tcni8 Ni-Based Alloy Database, Stockholm, Sweden, 2014

31. F. Zhang, L.E. Levine, A.J. Allen, M.R. Stoudt, G. Lindwall, E.A. Lass, M.E. Williams, Y. Idell, and C.E. Campbell: Acta Mater., 2018, vol. 152 , pp. $200-14$.
32. S.K. Rai, A. Kumar, V. Shankar, T. Jayakumar, K.B. Rao, and B. Raj: Scripta Mater., 2004, vol. 51, pp. 59-63.

33. C.C. Silva, H.C.D. Miranda, M.F. Motta, J.P. Farias, C.R.M. Afonso, and A.J. Ramirez: J. Mater. Res. Technol., 2013, vol. 2, pp. 228-37.

34. M.J. Cieslak, T.J. Headley, T. Kollie, and J.A.D. Romig: Metall. Mater. Trans. A, 1988, vol. 19A, pp. 2319-31.

35. L. Ferrer, B. Pieraggi, and J. F. Uginet: In Superalloys 718, 625 and Various Derivatives, ed. E.A. Loria, The Minerals, Metals \& Materials Society: Warrendale, PA, 1991, pp. 217-28.

36. G. Lindwall, C.E. Campbell, E.A. Lass, M.R. Stoudt, F. Zhang and L.E. Levine, In Preparation.

37. W.J. Sames, F.A. List, S. Pannala, R.R. Dehoff, and S.S. Babu: Int. Mater. Rev., 2016, vol. 61, pp. 315-60.

38. ASTM Designation E1621-13: Standard Guide for Elemental Analysis by Wavelength Dispersive X-Ray Fluorescence Spectrometry, ASTM International, West Conshohocken, PA, 2013, https:// doi.org/10.1520/E1621.

39. ASTM Designation E1059-11: Standard Test Methods for Determination of Carbon, Sulfur, Nitrogen, and Oxygen in Steel, Iron, Nickel, and Cobalt Alloys by Various Combustion and Fusion Techniques, ASTM International, West Conshohocken, PA, 2011, https://doi.org/10.1520/E1019-11. 